\title{
As relações econômicas internacionais do Brasil dos anos 1950 aos 80
}

Brazil's international economic relations, from 1950s to 1980 s

PAULO ROBERTO DE ALMEIDA*

Rev. Bras. Polít. Int. 50 (2): 60-79 [2007]

\section{As relações econômicas internacionais do Brasil em perspectiva histórica}

O presente ensaio resume as relaçōes econômicas internacionais do Brasil numa perspectiva de média duração, isto é, desde os anos 1950 até o final do regime militar, enfocando as questóes centrais da interface externa do Brasil nos planos comercial, financeiro, tecnológico e dos investimentos estrangeiros, com ênfase nos fluxos observados nessas áreas e nas tendências observadas no cenário internacional nas grandes fases desse itinerário.

As relaçôes econômicas internacionais podem ser conceitualmente definidas como fluxos que se estabelecem entre as economias nacionais atuando de forma interdependente no plano mundial, ainda que cada uma delas busque realizar o seu interesse exclusivo; vale aqui, no plano da economia internacional, o mesmo conceito de "mão invisível" que Adam Smith havia formulado para o funcionamento "normal" de uma economia de mercado: ainda que muitos acreditem ser globalização - que constitui o próprio núcleo da interdependência econômica - um processo dominado por um grupo restrito de países dominantes e de poderosas companhias, a verdade é que esse processo não é guiado por nenhum país ou nenhum grupo de atores em particular, buscando cada qual seu interesse egoísta exclusivo. As principais relações econômicas internacionais cobrem, principalmente, as seguintes áreas de foco setorial: comércio internacional, movimentos de capitais - puramente financeiros ou investimentos diretos -, migrações internacionais - isto é, deslocamentos de mão-de-obra - e intercâmbios tecnológicos, mais difíceis de serem medidos em função do caráter mais qualitativo desses fluxos (que, na verdade, se dão entre

\footnotetext{
* Professor de Economia Política no Mestrado em Direito do Centro Universitário de Brasília - Uniceub, doutor em Ciências Sociais pela Universidade de Bruxelas e diplomata de carreira (pralmeida@mac.com). Este ensaio contém opiniôes pessoais do autor.
} 
ou intra-empresas, nem sempre sendo computados nas estatísticas nacionais dos principais países da economia internacional) ${ }^{1}$

$\mathrm{O}$ que caracteriza as relações econômicas internacionais do Brasil nesse período é uma trajetória de inserção cautelosa, por vezes defensiva, na ordem econômica internacional, que se distingue por uma maior ou menor "inclusividade" em função das áreas objeto de maior ou menor controle por parte das autoridades encarregadas do processo decisório em cada uma delas. Essa inserção nos circuitos internacionais é maior ou menor em função dos ciclos de maior ou menor abertura - comercial, financeira etc. - que se observam ao longo do período, que é marcado por fases de expansão ou de crises nas economias centrais e seus reflexos nos sistemas econômicos ditos periféricos.

No plano dos intercâmbios de bens e serviços, essa inserção é feita, numa primeira fase, de uma participação limitada nos fluxos mais dinâmicos de comércio, ou apenas relevante em algumas linhas tradicionais de commodities exportadas pelo país, seguida de uma expansão relativamente satisfatória de produtos manufaturados labor ou resource-intensive, com alguma incidência, no período final, de produtos de alta tecnologia como os da indústria aeroespacial, mas aqui limitados às aeronaves civis da Embraer, um dos poucos exemplos de uma indústria de alta tecnologia competitiva no plano internacional. Esses processos são dominados pelo quadro institucional do GATT-1947, passando, depois de 1995, sob a responsabilidade da OMC, que passa a administrar um conjunto mais amplo de acordos econômicos multilaterais. No plano das finanças internacionais, o quadro jurídico é dado pelos arranjos institucionais de Bretton Woods, cujo esquema monetário e cambial, administrado pelo FMI até 1973, converte-se, na verdade, num não-sistema financeiro internacional em virtude da flutuação generalizada das moedas; o Brasil faz apelo freqüente a fontes externas de financiamento internacional, seja sob a forma bilateral de credores oficiais, seja ao abrigo de esquemas multilaterais de financiamento ao desenvolvimento, seja ainda recorrendo aos mercados comerciais de financiamento privado.

\footnotetext{
1 Para o estudo das relações econômicas internacionais ou, de modo amplo, da evolução da economia mundial, recomenda-se a consulta a algumas obras de referência nesta área: A. G. Kenwood e A. L. Loughheed, The Growth of International Economy, 1820-2000: an introductory text, 4a. ed.; Londres: Routledge, 2001; Jean-Louis Mucchielli, Relations Économiques Internationales, 2a. ed.; Paris: Hachette, 1994; Herman Van Der Wee, Histoire Économique Mondiale, 1945-1990, Louvain-la-Neuve: Academia Duculot, 1990; Angus Maddison, The World Economy: A Millenial Perspective, Paris: Development Centre of the OECD, 2001; James Foreman-Peck, A History of the World Economy, 2a. ed.; New York: Financial Times Prentice Hall, 1994; Rondo Cameron, World Economic History. 3a . ed.; Oxford: Oxford University Press, 1989; Barry Eichengreen, A Globalização do Capital, São Paulo: Editora 34, 2002; Harold James, International Monetary Cooperation since Bretton Woods. Washington: International Monetary Fund/New York: Oxford University Press, 1996; Charles P. Kindleberger, World Economic Primacy: 1500 to 1990. New York: Oxford University Press, 1996; Nathan Rosenberg e L. E. Birdzell Jr., How the West Grew Rich. New York: Basic Books, 1986; David Landes, A Riqueza e a Pobreza das Naçôes: por que algumas são tão ricas e outras são tão pobres. Rio de Janeiro: Campus, 1996.
} 
Não existe, para a área tecnológica e dos investimentos privados nenhum esquema de regulação mundial, a não ser os acordos bilaterais de proteção de investimentos (APPIs) e os mecanismos flexíveis administrados pela OMPI no terreno da propriedade intelectual - convenções de Paris e de Berna, entre outros instrumentos -, até o aparecimento, já nos anos 1990, dos compromissos assumidos em Trips e Trims, sob a égide da Rodada Uruguai. O Brasil é um grande receptor de investimentos diretos estrangeiros e um observador satisfatório dos princípios de proteção à tecnologia proprietária, com poucas exclusões e infraçôes aos interesses multinacionais. Na mão-de-obra, o Brasil se converte de grande importador de imigrantes, o que ele foi nas primeiras décadas do século, em um exportador moderado de força de trabalho não especializada em direção de algumas das principais economias que tinham alimentado seu fluxo imigratório um século antes, com o acréscimo, nos fluxos emigratórios, dos Estados Unidos.

O que revela o estudo desses fluxos e movimentos de bens, serviços, capitais e recursos humanos, para dentro e para fora do Brasil, é a existência de padrōes de maior ou menor expansão da economia nacional, traduzidos em taxas diferenciadas de crescimento econômico, maiores ou menores segundo as épocas, tanto em função de oportunidades oferecidas pelo sistema econômico internacional em determinadas fases, como em virtude do ambiente interno, que é determinados pelas políticas econômicas. Na perspectiva do longo prazo, há uma nítida trajetória de desenvolvimento errático da economia nacional, com aceleração do processo de crescimento em algumas fases - grosso modo, o final dos anos 1950 e novamente uma década depois e no decorrer dos anos 1970 - e crises econômicas em outras fases, acarretadas tanto por desequilíbrios externos - na maior parte dos casos por "estrangulamento" cambial -, como em razão do descontrole inflacionário interno. O ritmo do crescimento brasileiro diminuiu bastante no final do período, caracterizado por acentuada fragilidade financeira externa que só seria superada nos primeiros anos do século XXI, com uma administração mais cautelosa no plano da dívida externa e um comportamento mais responsável no plano fiscal.

No que se refere à bibliografia disponível, o ponto de partida pode ser fixado pelo ensaio de Pedro Malan, no último volume da "História Geral da Civilização Brasileira", que examina, precisamente, as relações econômicas internacionais do Brasil no período anterior ao coberto no presente ensaio. ${ }^{2}$ Cabe ainda referência às obras organizadas por Marcelo de Paiva Abreu, Paulo Neuhaus, Fabio Giambiagi, Amaury Gremaud e outros, ${ }^{3}$ assim como aos depoimentos ou compilações de artigos

2 Pedro Sampaio Malan, "Relaçōes Econômicas Internacionais do Brasil (1945-164)" in Boris Fausto (org.), História Geral da Civilização Brasileira, Tomo III: O Brasil Republicano, $4^{\circ}$ vol.: Economia e Cultura, 1930-1964, 2a ed., São Paulo, Difel, 1986, pp. 51-106.

3 Marcelo de Paiva Abreu (org). A Ordem do Progresso: cem anos de politica econômica republicana, 1889-1989, Rio de Janeiro: Campus, 1990; Paulo Neuhaus (coord.), Economia brasileira: uma visäo histórica, Rio de Janeiro: Campus, 1980; Fabio Giambiagi, André Villela, Lavínia Barros de Castro e Jennifer Hermann (orgs.), Economia Brasileira Contemporânea (1945-2004), Rio de Janeiro: Elsevier, 2005; Amaury Patrick Gremaud, Marco Antonio Sandoval de Vasconcellos e Rudinei Toneto Júnior, Economia Brasileira Contemporânea, 5 a ed.; São Paulo: Atlas, 2004. 
ilustrativos do itinerário histórico aqui coberto, ${ }^{4}$ ademais de trabalhos anteriores do autor, que apresentam conexão com os temas aqui tratados. ${ }^{5}$ Uma consulta a séries estatísticas dos principais indicadores econômicos, a maior parte das quais pode ser encontrada nas últimas páginas da revista mensal Conjuntura Econômica ou nas bases de dados do IBGE, é, obviamente, indispensável para reconstituir alguns dados relevantes para sustentar os argumentos expostos neste ensaio.

\section{Uma caracterização inicial das relações econômicas internacionais do Brasil}

No primeiro volume do seu Princípios de Economia Monetária (2 ${ }^{a}$ edição publicada em 1947), o então professor da Faculdade Nacional de Ciências Econômicas da Universidade do Brasil, Eugenio Gudin, incluiu um capítulo sobre o "balanço de pagamentos do Brasil" (cap. XX, do "Livro IV: Teoria dos Câmbios Internacionais"), no qual ele resumiu o que lhe pareciam ser os traços característicos das relaçôes econômicas internacionais do Brasil. Essas características, válidas para os anos 1950 e início dos anos 60, foram por ele assim definidas:

1) Importaçôes rígidas: feitas basicamente de trigo, petróleo, carvão energético e de matérias primas e equipamentos para as indústrias, sem possibilidades de substituição, portanto;

2) Ingresso absolutamente necessário de capitais estrangeiros: para juros e amortizações, normalmente associados a investimentos físicos, mas ele alertava para o mau uso desses recursos, derivado dos déficits orçamentários, tanto quanto para o protecionismo exagerado, que podia afetar as exportações, necessárias para o pagamento das rendas desses capitais;

3) Procura inelástica pelos principais produtos de exportação do Brasil: situação que só podia ser compensada por uma situação semimonopolista no fornecimento de algum produto, o que ocorria parcialmente no caso do café, base inegável das receitas de exportação nesses anos;

4) Inelasticidade na oferta dos produtos de exportação: em virtude do caráter perene ou da dependência "meteorológica" das principais culturas - entre elas o café - ou de deficiências no sistema de transportes, o que afetava, por exemplo, a exportação de minérios.

\footnotetext{
4 Ver, por exemplo: Roberto de Oliveira Campos, A Lanterna na Popa: memórias, 2a ed.; Rio de Janeiro: Topbooks, 1994; Mario Henrique Simonsen e Roberto de Oliveira Campos, A Nova economia brasileira, $3^{\mathrm{a}}$ ed.; RJ: José Olympio, 1979; Mário Henrique Simonsen, Textos escolhidos, Rio de Janeiro: FGV, 2002; João Paulo dos Reis Velloso, O Último Trem para Paris: de Getúlio a Sarney, "milagres”, choques e crises do Brasil moderno, Rio de Janeiro: Nova Fronteira, 1986; Idem, Tempos modernos: memórias do desenvolvimento, Rio de Janeiro: FGV, 2004. 5 Ver, por exemplo: Formação da diplomacia econômica no Brasil, 2a ed.; São Paulo: Senac, 2005; Relaçôes internacionais e politica externa do Brasil, 2a ed.; Porto Alegre, 2004; Os primeiros anos do século XXI: o Brasil e as relaçôes internacionais contemporâneas, São Paulo: Paz e Terra, 2002; O Brasil e o multilateralismo econômico, Porto Alegre: Livraria do Advogado, 1999; O Mercosul no contexto regional e internacional, São Paulo: Edições Aduaneiras, 1993
} 
5) Baixa diversidade da pauta exportadora: o que ocasionava grandes flutuações nas receitas exportadoras e no mercado de câmbio, sem possibilidade de compensaçôes imediatas;

6) Economia "reflexa" do Brasil, submetida, portanto, às flutuaçóes normais dos ciclos econômicos nos países desenvolvidos, nossos principais parceiros econômicos: a conjuntura de retração nos preços internacionais de nossos principais produtos de exportação não apenas piorava as relações de troca e provocava a baixa do câmbio, como também reduzia o ingresso de capitais estrangeiros, trazendo problemas para a balança de capitais;

7) Deterioração nas relações de troca em virtude da desvalorização da moeda nacional, por causa da inflação interna: situação que afetava basicamente o principal produto exportado, o café, bastante concentrado no mercado dos EUA, responsável, então, por mais de $40 \%$ das nossas exportações e mais de um terço da demanda por importaçóes;

8) Desvalorização cambial contínua: alimentada pelo que Gudin chamava de "inflação crônica ou semicrônica”, encarecendo os produtos de importação; essa situação beneficiava os industriais nacionais e os exportadores, chamados por ele de "dois grupos poderosos a se beneficiar"; ele também comparava essa situação com a grande inflação alemã dos anos 1922-23. ${ }^{6}$

No segundo volume, Gudin incluiu uma seção sobre o "comportamento cíclico do Brasil". Nele, Gudin confirma que "o comportamento cíclico de nosso país é o de uma economia reflexa", porque, "com uma exportação de perto de $20 \%$ de sua renda nacional, o impacto cíclico vindo do exterior faz-se sentir no Brasil com bastante intensidade, particularmente se for o movimento cíclico originário dos Estados Unidos, país com o qual nossas relações de comércio e de capitais são estreitas". 7 Acrescentava Gudin que era claro "que países como o nosso não podem ter qualquer responsabilidade na origem dos ciclos mundiais, que é matéria privativa das economias líderes". Ele também considerava que não se aplicava ao caso brasileiro a possível escassez de investimentos: "ao contrário, a nossa desordem econômica e monetária, como a nossa inflação endêmica, têm sido, em grande parte, causadas pela sofreguidão de tudo querermos executar ao mesmo tempo, sem atender sequer ao fato de que os nossos fatores de produção, como os de todo o mundo, são limitados". Ele terminava dizendo que os impactos dos ciclos mundiais no Brasil acabavam se superpondo aos efeitos dos "desequilíbrios de origem doméstica, não raro graves, de que padece repetidamente a nossa economia". ${ }^{8}$

6 Cf. Eugenio Gudin, Princípios de Economia Monetária. 2a. ed.; Rio de Janeiro: Livraria Agir, 1947; sem menção de ser o primeiro volume, mas já com o anúncio da preparação de um segundo, então em curso de redação; ver p. 273-277.

7 Cf. Eugenio Gudin, Princípios de Economia Monetária, 2º volume. 2a. ed.; Rio de Janeiro: Livraria Agir, 1956, ver p. 174-175.

8 Idem, loc. cit., p. 175. 
Cabe ressaltar que, com a possível e parcial exceção da diminuição do possível impacto dos ciclos externos na economia brasileira, em razão da diminuição do coeficiente de abertura externa nos anos, e décadas, que se seguem à redação de suas duas obras de "política monetária" - na verdade, um curso inteiro de economia, numa fase em que os manuais disponíveis eram quase todos importados da França ou dos Estados Unidos -, a maior parte das observaçôes feitas pelo grande economista brasileiro do século XX permanece inteiramente válida durante quase todo o período aqui examinado, com uma gradual mudança nas relaçóes de troca ao longo dos anos, em função do processo de industrialização, da substituição consequiente de importações e da crescente diversificação da pauta exportadora, o que não retirou, contudo, o grande peso ainda registrado na composição primária de grande parte das receitas de exportações. Quanto ao câmbio, ele parece ter libertado-se de manipulações governamentais, das desvalorizações que sempre realimentaram o processo inflacionário - um "prêmio" dado à ineficiência produtiva do industrial nacional - e dos controles extensivos sobre os movimentos de capitais, para ingressar num regime teoricamente "puro" de flutuação, que na verdade valoriza o poder de compra da moeda nacional, para maior tranqüilidade das autoridades monetárias e dos líderes políticos, contentes com o auxílio no combate inflacionário e a revalorização dos salários nacionais.

O período de pouco mais de meio século que nos separa das obras de Gudin confirma alguns dos traços característicos das relações econômicas internacionais do Brasil, tanto quanto introduz a noção da perspectiva histórica na avaliação que se possa fazer dos últimos cinqüenta anos de itinerário econômico nacional, nas interfaces da economia brasileira com a economia mundial. Cabe, assim, destacar, as continuidades e mudanças ocorridas nos padrões de comércio, nos movimentos de capitais, nos padrões de intercâmbio tecnológico, na importação ou exportação de cérebros e de know-how, bem como no relacionamento com os organismos econômicos do multilateralismo contemporâneo e com as principais praças fornecedoras de capitais financeiros, com destaque para a famosa questão da "vulnerabilidade financeira externa", fantasma constantemente agitado nos livros e artigos de economia desde a crise dos anos 1930 e o gradual fechamento da economia brasileira aos "ciclos econômicos do exterior".

\section{Dependência sem admissão: de meados dos anos 1950 à ruptura de 1964}

A economia internacional ingressa numa fase de expansão nas três décadas seguintes à Segunda Guerra, com o aumento do comércio e dos investimentos diretos ultrapassando o ritmo de crescimento do produto global. Os Estados Unidos, que tinham emergido como a grande potência econômica no imediato pós-guerra - detendo cerca de $25 \%$ do produto e do comércio mundiais - recuam para posições mais modestas no decorrer do período, à medida que o Japão e os 
países europeus retomam os patamares de produção anteriores à guerra e passam a participar mais ativamente dos intercâmbios globais. O dólar se tinha convertido em moeda absoluta nas trocas internacionais, o que suscitou algumas dúvidas sobre seu real poder de compra, uma vez que o governo americano, pressionado pelas despesas dos encargos militares assumidos no plano mundial, passou a emitir em ritmo superior ao crescimento da produtividade na economia dos EUA. $\mathrm{O}$ ordenamento institucional que preside a essa fase de expansão econômica, em grande medida impulsionada pela reconstrução dos países destruídos pela guerra mas também permitida pela liberalização ampla dos intercâmbios, é dado pelos chamados organismos de Bretton Woods - FMI e Banco Mundial -, mas também pelo GATT, o acordo geral de tarifas e comércio, consagrando a cláusula de nação-mais-favorecida em bases incondicionais e irrestritas.

O Brasil aderiu a todas essas organizaçōes multilaterais, mas de fato mantinha, numa primeira fase, um perfil discreto nos processos decisórios, em função da reduzida diversificação de sua economia. As duas principais commodities produzidas no país ainda respondiam por mais de $60 \%$ da pauta exportadora em meados dos anos 1950. Devido à flutuação dos seus preços nos mercados internacionais, os termos de troca eram essencialmente erráticos, impactando de modo negativo as receitas em divisas com as quais se tinham de cobrir as importaçóes obrigatórias e o serviço da dívida externa. Ainda assim, o coeficiente de vulnerabilidade externa - anos de exportações para o pagamento da dívida diminui bastante no período imediatamente após a guerra, para voltar a crescer aceleradamente a partir de meados dos anos 1950.

O café se valorizou significativamente com a guerra da Coréia (1950-53), mas voltou a cair na segunda metade da década. Ele ainda representava 69\% do total das exportaçôes totais em 1956 e 56\% em 1960 e o Brasil ainda respondia por mais de um terços das vendas mundiais do produto, mas sua importância no PIB cai significativamente ao longo do período, ao ter início a forte aceleração do processo industrializador, com o Plano de Metas do governo Kubitschek. A política cambial não favorecia as exportações, que decresceram $2,3 \%$ ao ano nesse período, ao passo que as importações aumentavam a uma taxa anual de $3,2 \%$. O resultado foi um grande déficit em conta corrente, sem mencionar o enorme déficit nas contas públicas e a aceleração da inflação como resultado dos gastos correntes e grandes investimentos do período. O Plano de Metas cumpriu satisfatoriamente seus objetivos, mas a política comercial tornou-se abertamente protecionista, com a introdução de uma nova tarifa, em 1957, que praticamente obrigou o Brasil a renegociar sua adesão ao GATT.

$\mathrm{O}$ impulso na industrialização se deveu à combinação de políticas que promoveram a substituição de importações, com estímulos vindos da política comercial protecionista, e da atração do capital estrangeiro, emblemático no caso $\mathrm{da}$ indústria automobilística. $\mathrm{O}$ total do investimento direto estrangeiro (IED) passa de uma média anual de US\$ 64 milhões, de 1950 a 1955, para uma média 
anual de US\$ 150 milhões, entre 1956 e 1960. A dependência brasileira em relação a capitais, tecnologia e know-how estrangeiro jamais ficou tão visível como nessa fase, situação aliás reconhecida pelo próprio Plano de Metas de JK, cuja implementação assiste a um movimento ascensional da participação da poupança externa na taxa de investimento total, como se pode constatar na tabela abaixo.

Investimento estrangeiro direto e poupança externa, 1950-1960

\begin{tabular}{l|r|r|r|r|r|r|r|r|r|r|r}
\hline & 1950 & 1951 & 1952 & 1953 & 1954 & 1955 & 1956 & 1957 & 1958 & 1959 & 1960 \\
\cline { 2 - 10 } IED (US\$ milhões) & 39 & 63 & 94 & 60 & 51 & 79 & 139 & 178 & 128 & 158 & 138 \\
\hline Poupança Ext./PIB & $-0,62$ & 2,66 & 3,31 & 0,10 & 2,11 & 0,31 & 0,16 & 1,78 & 2,17 & 2,25 & 3,03 \\
\hline
\end{tabular}

Fontes: IBGE e Banco Central, in Giambiagi et alii (orgs.), Economia Brasileira Contemporânea.

Os anos 1950 também foram a última década na história do Brasil na qual o ingresso líquido de imigrantes foi relevante para o incremento populacional brasileiro, ainda que com uma contribuição (em torno de 3,25\% do crescimento demográfico total, nessa época de $2,59 \%$ ) bem inferior àquelas conhecidas no final do século XIX e primeiras décadas do XX. Paulatinamente, o Brasil foi deixando de receber as levas de imigrantes europeus que tinham auxiliado de maneira decisiva o processo de modernização produtiva e cultural, até adotar políticas migratórias bem mais restritivas do que tinha sido o caso até então. Nas décadas seguintes, essa contribuição líquida desapareceria, até o Brasil se converter em exportador moderado de mão-de-obra.

A literatura econômica relativa ao período JK costuma caracterizar o seu modelo de desenvolvimento como tendo sido um abandono do antigo projeto nacional-desenvolvimentista da era Vargas e a assunção deliberada de um modelo "associado e dependente", caracterizado por forte processo de "internacionalização" da economia brasileira. ${ }^{9}$ Quaisquer que tenham sido os resultados em termos de "subordinação" da economia brasileira ao que esses autores chamam de "capitalismo monopolista internacional”, o fato é que o forte impulso na industrialização ocorrido nos anos JK diminuiu bastante - inclusive por preocupaçóes constantes das autoridades vis-à-vis o "estrangulamento externo", isto é uma crise cambial - a "dependência" do processo produtivo em relação a insumos importados, a ponto de se poder falar de uma "autarquização" da economia, menos, provavelmente, por tendências naturais da organização industrial do que por decisões deliberadas de política econômica orientadas no sentido do protecionismo comercial e da

9 Ver, por exemplo, entre muitos outros ensaios de interpretação das transformaçóes da economia brasileira nesse período, que tomam como paradigma a análise conduzida por Maria da Conceição Tavares em Da Substituição de Importações ao Capitalismo Financeiro: ensaios sobre a economia brasileira (Rio de Janeiro: Zahar, 1975), o livro-síntese de Marina Gusmão de Mendonça e Marcos Cordeiro Pires, Formação Econômica do Brasil (São Paulo: Pioneira Thomson Learning, 2002). 
substituição efetiva das importaçōes. A tabela seguinte dá uma idéia do forte movimento hacia adentro nas três décadas que se seguiram à Segunda Guerra.

Importações sobre oferta total de bens industriais, 1949-1964 (\%)

\begin{tabular}{c|c|c|c|c|c}
\hline \multirow{2}{*}{ Ano } & \multicolumn{2}{|c|}{ Bens de consumo } & \multicolumn{2}{c|}{ Bens de produção } & \multirow{2}{*}{$\begin{array}{c}\text { Total de bens } \\
\text { industriais }\end{array}$} \\
\cline { 2 - 5 } & não duráveis & duráveis & intermediários & capital & 19,0 \\
\hline 1949 & 3,7 & 64,5 & 25,9 & 63,7 & 11,1 \\
\hline 1955 & 2,2 & 10,0 & 17,9 & 43,2 & 9,7 \\
\hline 1959 & 1,1 & 6,3 & 11,7 & 32,9 & 4,2 \\
\hline 1964 & 1,2 & 1,6 & 6,6 & 9,8 & \\
\hline
\end{tabular}

Fonte: Bergsman e Malan ${ }^{10}$, reproduzido em Gremaud, Economia Brasileira Contemporânea, p. 369.

As taxas de crescimento econômico do governo JK, sobretudo as do setor industrial, foram bastante altas, mas isso se fez ao preço do desequilíbrio das contas públicas e da elevação generalizada dos preços. Um "Plano de Estabilização Monetária", sob inspiração do FMI, foi tentado em 1958, prevendo moderação nos reajustes salariais, contenção das despesas públicas - inclusive as onerosas compras de excedentes de café - e a unificação do câmbio, que desde 1953 funcionava oficialmente segundo um regime de taxas múltiplas. A diminuição dos subsídios às importações de gasolina e trigo repercutiu no custo de vida, o que levou JK a abandonar o plano e a "romper" as negociaçóes com o FMI. No seu período as exportações diminuíram quase $15 \%$ e a dívida externa cresceu $50 \%$, chegando a 2,7 vezes as exportaçôes totais em 1960.

Jânio Quadros inicia o seu governo, em 1961, com uma forte desvalorização cambial, a unificação das taxas e uma série de medidas ortodoxas, bem recebidas pelos credores externos. Sua renúncia, após seis meses, impediu a continuidade do programa de estabilização e o clima de crise política vivido pelo governo João Goulart não contribuiu, obviamente, para a recuperação das taxas de crescimento. Um "Plano Trienal de Desenvolvimento Econômico e Social", elaborado por uma equipe liderada por Celso Furtado, pretendia demonstrar "contra a ortodoxia dos monetaristas, esposada e imposta pelo FMI, que era possível conduzir a economia com relativa estabilidade sem impor-lhe a purga recessiva". A deterioração da situação externa não pôde ser contida com nova ajuda dos credores, inclusive porque a aprovação da lei de remessa de lucros, em 1962, limitava em 10\% do capital registrado as remessas dos investidores estrangeiros.

A chamada "política externa independente" também pode ter contribuído para a pouca simpatia despertada em relação aos pleitos junto ao principal credor. Uma missão do ministro da Fazenda, San Tiago Dantas, a Washington, em

10 J. Bergsman; P. Malan, "The Structure of Protection in Brazil" in Bela Balassa, The Structure of Protection in Developing Countries (Baltimore: The Johns Hopkins Press, 1971). 
março de 1963, solda-se por um fracasso: dos US\$ 600 milhōes solicitados, ele só obtém US\$ 84 milhões, e não consegue renegociar os prazos para o pagamento da dívida externa. As conseqüências se fizeram sentir logo em seguida, com uma deterioração sensível da situação macroeconômica: a inflação deixa a casa dos 20 a 40\% ao ano no período JK para o dobro desse percentual nos anos 1963 e 1964. A poupança externa decai como proporção do PIB, os fluxos de IED voltam a declinar e as taxas de investimento e de crescimento também caminham para baixo. As condições estavam dadas para a mudança política.

\section{A recomposição da ordem econômica e a nova inserção internacional}

O regime militar começou a atuar em clima de estagnação econômica e de aceleração inflacionária, justificando preocupações no campo da estabilização e da correção de rumos. Os esforços de estabilização econômica, por meio do Plano de Ação Econômica do Governo (PAEG), na gestão do general Castelo Branco (196467), atuou no plano dos instrumentos básicos de política econômica, como a política monetária, mas também foram atacadas as causas estruturais da inflação. Optou por um combate progressivo ou gradual à inflação e se procurou, por outro lado, incentivar as exportações, via política cambial, e os investimentos estrangeiros.

O período que vai de 1964 a 1973 apresenta duas fases bem distintas, tanto no plano interno, como na interface externa, com um primeiro sub-período (196467) marcado pelo esforço de estabilização, em nítido contraste com a arrancada conseguida na fase ulterior (1968-1973), como se pode constatar na tabela seguinte.

Comportamento da economia brasileira, 1964-1973

\begin{tabular}{l|c|c}
\hline \multicolumn{1}{c|}{ Indicadores macroeconômicos } & $\begin{array}{c}\text { Médias } \\
1964-67\end{array}$ & $\begin{array}{c}\text { Médias } \\
1968-73\end{array}$ \\
\hline Crescimento do PIB (\% ao ano) & 4,2 & 11,1 \\
\hline Inflação (IGP, dez./dez, \% ao ano) & 45,5 & 19,1 \\
\hline Formação bruta de capital fixo (\% PIB) & 15,5 & 19,5 \\
\hline Taxa de crescimento das exportações (\% a.a, US\$) & 4,1 & 24,6 \\
\hline Taxa de crescimento das importações (\% a.a, US\$) & 2,7 & 27,5 \\
\hline Balança comercial (US\$ milhões) & 412 & 0 \\
\hline Saldo em conta corrente (US\$ milhões) & 15 & -1.198 \\
\hline Dívida externa líquida/Exportações de bens & 2,0 & 1,8 \\
\hline
\end{tabular}

Fonte: Dados do IBGE, elaborados por Jennifer Hermann ${ }^{11}$.

11 Ver Jennifer Hermann, “Reformas, Endividamento Externo e o 'Milagre’ Econômico (1964-1973)” in Fabio Giambiagi, Jennifer Hermann et alii (orgs.), Economia Brasileira Contemporânea, op. cit., p. 69-92, cf. 79. 
As mudanças introduzidas pelo novo governo afetaram sobretudo o tratamento dado aos investimentos estrangeiros, uma vez que o modelo substitutivo, ainda que corrigido pela ênfase dada às exportaçóes, foi mantido ao longo do regime militar. Uma das primeiras medidas adotadas pelo governo militar foi a modificação dos artigos 31 a 33 da Lei 4131, ou Estatuto do Capital Estrangeiro (1962), eliminando as limitações até então impostas à remessa dos lucros (10\% do capital registrado) e a proibição da remessa de dividendos relativos aos reinvestimentos (Lei 4390, de 29.08.64). Uma Instrução da SUMOC (289), adotada logo em seguida, facilitou as operações em moedas conversíveis, abrindo uma nova fonte de crédito para empresas estrangeiras, ao passo que o mercado interno de crédito era reservado às empresas nacionais.

As mudanças na política econômica, inclusive no setor externo, foram muitas e importantes, conquanto graduais e delongadas ${ }^{12}$. Nas áreas da política cambial e do comércio exterior se perseguia o equilíbrio das contas externas e a diversificação das fontes de suprimento; a política de consolidação da dívida externa atuou conjuntamente com a restauração do crédito do Brasil no exterior; também se promoveu uma política de estímulo ao ingresso de capitais estrangeiros e se buscou uma ativa cooperação técnica e financeira com as agências financeiras internacionais; as políticas monetária e fiscal, em contrapartida, foram contracionistas ${ }^{13}$. Uma das reformas mais importantes, sem dúvida alguma, foi a do sistema financeiro nacional, com a criação do Banco Central (Lei 4.595/65).

A política cambial acompanhou o retorno gradual ao realismo econômico. Em maio de 1964, a Instrução 270 da SUMOC unificou as operações cambiais que ainda se beneficiavam de taxas especiais (trigo, petróleo, papel de imprensa). Mas, entre o final desse ano e 1968, a taxa de câmbio permanece fixa durante largos intervalos de tempo, a despeito do processo inflacionário, com reajustes ocasionais ao longo do período. Em agosto de 1968, finalmente, passa-se a um novo regime cambial, baseado em minidesvalorizaçôes, sistema mantido com poucas alterações - em dezembro de 1979, ocorreu uma maxidesvalorização de $30 \%$, aliás tornada inócua pela prefixação da taxa no curso de $1980^{14}$ - durante largo tempo, até praticamente 1994 (Plano Real).

As autoridades econômicas buscaram normalizar as relações do Brasil com os credores internacionais, tanto no plano bilateral, no âmbito do Clube de

12 Como confirmou um dos principais formuladores econômicos do governo, o à época ministro do planejamento Roberto Campos, "[o] Fundo Monetário Internacional não aceitava o gradualismo. Sugeria um tratamento de choque. Nós argumentávamos que o tratamento de choque era impraticável e que os modelos europeus de cura súbita da inflação não eram aplicáveis ao caso brasileiro..."; in Ciro Biderman, Luis Felipe L. Cozac e José Marcio Rego, Conversas com Economistas Brasileiros. São Paulo: Editora 34, 1996, "1. Roberto de Oliveira Campos", pp. 31-59, cf. p. 49.

13 Cf. André Lara Resende, "Estabilização e reforma: 1964-1967” in Marcelo de Paiva Abreu (org.), A Ordem do Progresso, op. cit., p. 213-231.

14 Cf. Fernando de Holanda Barbosa, A Inflação Brasileira no Pós-Guerra: Monetarismo versus Estruturalismo. Rio de Janeiro: IPEA-INPES, 1983, p. 61. 
Paris, como na esfera multilateral, com as entidades de Bretton Woods. O Banco Mundial, a partir dessa época, também passou a emprestar com maior liberalidade ao Brasil, assim como o Eximbank, o banco governamental de financiamento de exportações, e a AID, a agência oficial de ajuda ao desenvolvimento do governo dos EUA. Entre 1965 e 1972 foram negociados sucessivos acordos stand-by com o Fundo, praticamente ano a ano.

$\mathrm{Na}$ verdade, esses acordos não eram necessários do ponto de vista estrito do balanço de pagamentos, justificando-se apenas como uma espécie de "selo de qualidade" das políticas econômicas implementadas nessa fase de estabilização. Dos quase 570 milhões de direitos especiais de saque (DES) concedidos nessa época, em oito operações anuais, o Brasil sacou apenas 150 milhōes (em duas fatias de 75 milhões, as primeiras sem condicionalidades), contentando-se o governo com o aval do FMI para fins de renegociação da dívida com os credores oficiais do Clube de Paris. Ressalte-se que o Brasil mantinha um regime cambial formalmente em desacordo com as regras de Bretton Woods, uma vez que baseado no ajuste gradual da paridade externa da moeda nacional, em face do sistema de estabilidade em princípio em vigor desde o final dos anos 1940.

\section{O Brasil no contexto econômico do grande crescimento mundial pré-1973}

Caberia colocar o processo de desenvolvimento brasileiro desses anos no contexto do crescimento do comércio mundial e da intensificação dos fluxos financeiros internacionais, tanto sob a forma dos investimentos diretos como na modalidade dos empréstimos comerciais. A economia mundial conheceu três décadas de expansão, quando a recuperação européia já tinha sido alcançada, suas moedas ganhado conversibilidade, com poucas pressões protecionistas, numa fase de redução negociada das barreiras tarifárias entre os grandes parceiros comerciais. O Brasil beneficiou-se relativamente do crescimento generalizado do período anterior aos choques do petróleo dos anos 1970, talvez mais pelo lado da importação de capitais e de tecnologia, do que propriamente pela sua inserção nos fluxos mais dinâmicos do comércio internacional, mesmo se a pauta exportadora foi sendo progressivamente diversificada desde os anos 1960.

A entrada de IED sai da casa US\$ 127 milhões anuais, em média, entre o início da década e 1968, quando os sinais indicam uma economia novamente estabilizada e pronta para o crescimento, para uma média de US\$ 525 milhóes na fase do "milagre econômico", entre 1969 e 1973. A tabela abaixo compila os dados relativos a esses influxos, podendo-se constatar, ademais, a elevação do peso na poupança externa na formação bruta de capital fixo. 
Investimento estrangeiro direto e poupança externa, 1961-1973

\begin{tabular}{|c|c|c|c|c|c|c|c|c|c|c|c|c|c|}
\hline & 1961 & 1962 & 1963 & 1964 & 1965 & 1966 & 1967 & 1968 & 1969 & 1970 & 1971 & 1972 & 1973 \\
\hline IED (US\$ milhões) & 147 & 132 & 87 & 86 & 154 & 159 & 115 & 135 & 207 & 378 & 448 & 441 & 1.148 \\
\hline oupança Ext./PIB & 1,53 & 2,34 & 0,73 & $-0,39$ & $-1,26$ & 0,11 & 0,89 & 1,72 & 0,98 & 1,98 & 3,34 & 2,89 & 2,50 \\
\hline
\end{tabular}

Fontes: IBGE e Banco Central, in Giambiagi et alii (orgs.), Economia Brasileira Contemporânea.

Com a estabilização da economia e a abertura econômica, tem início uma fase de influxos crescentes de capitais externos, justificando-se, inclusive, a adoção moderada de alguns mecanismos de esterilização parcial dos recursos em divisas. Entre 1967 e 1973, data do primeiro choque do petróleo, foram introduzidas “importantes mudanças nas áreas do comércio exterior, da dívida externa e do investimento estrangeiro no Brasil. Parte dessas mudanças está associada com medidas de política econômica, tais como a política cambial e a política de incentivos às exportaçôes, mas fatores exógenos como o crescimento da economia mundial, a evolução favorável dos termos de troca e uma crescente liquidez no mercado internacional de capitais também tiveram importante impacto positivo sobre as principais contas externas do país" ${ }^{\prime 15}$.

No plano financeiro, observa-se uma escalada do endividamento externo, com a quadruplicação da dívida entre 1966 - US\$ 3,66 bilhōes, incluindo reservas de 412 milhões - e 1973, quando a dívida bruta alcançou US\$12,57 bilhōes. ${ }^{16} \mathrm{~A}$ relação entre a dívida líquida e as exportações não era tão elevada, tendo declinado no período, mas o serviço da dívida passou a assumir um peso crescente, com o aumento no pagamento dos juros. "Estava lançado o processo de aumento de participação dos empréstimos a taxas de juros flutuantes no total dos empréstimos externos e de redução das taxas concessionais, fixas, dos organismos internacionais, que teria efeitos dramáticos no final da década de 70"17.

\section{Política comercial e crescimento das exportações: a grande mudança}

No período anterior ao regime militar, o Brasil continuava a ser, aliás como desde meados do século XIX, basicamente um vendedor de café, produto que ainda compunha $60 \%$ da pauta exportadora no início dos anos 1960. Depois de ensaios frustrados na era da Liga das Nações, teve início, nos anos 1950, a negociação dos primeiros acordos de produtos de base - café, cacau, açúcar, entre outros -, com a criação concomitante das organizações multilaterais setoriais

15 Ver Luiz Aranha Corrêa do Lago, "A retomada do crescimento e as distorçōes do 'milagre': 1967-1973" in Abreu (org.), A Ordem do Progresso, op. cit., p. 233-294, cf. p. 272.

16 Depois de se situarem em torno de US\$ 540 milhões entre 1969 e 1971, as reservas líquidas sobem a mais de US\$ 2.300 milhões em 1972 e 1973; cf. José Eduardo Carvalho Pereira, Financiamento Externo e Crescimento Econômico no Brasil: 1966/73. Rio de Janeiro: IPEA/INPES, 1974, p. 49.

17 Cf. Lago, “A retomada do crescimento...", op. cit., p. 281. 
que passaram a se ocupar desses produtos, processo no qual o Brasil foi um dos principais protagonistas. Ainda no terreno da diplomacia comercial multilateral, essa fase corresponde aos primeiros exercícios negociadores de mudanças no texto original do Acordo Geral de Tarifas Aduaneiras e Comércio (Gatt-1947), do qual o Brasil era membro fundador. Tendo adotado novos princípios de política comercial e cambial a partir de 1953, o Brasil teve praticamente de renegociar sua adesão ao Acordo, a partir da nova Lei Aduaneira e de reclassificação tarifária, adotada em 1957.

No âmbito regional, a fase também é marcada por mudanças de ênfase nos planos comercial e industrial. Com a consolidação de um corpo de economistas competente na sede da Comissão Econômica para a América Latina (Cepal), em Santiago, sob a liderança do economista argentino Raúl Prebisch, toma impulso o chamado "modelo cepalino", isto é, a promoção do desenvolvimento nacional por meio de políticas ativas de industrialização, eventualmente mediante a cooperação econômica no contexto sul-americano e a promoção de esquemas de integração. Tais esforços, inclusive por um certo mimetismo em relação ao mercado comum europeu instituído em 1957, resultarão, em 1960, na criação da Associação Latino-Americana de Livre-Comércio (Alalc).

Esse período coincide com reiteradas demandas, por parte dos países então chamados de subdesenvolvidos, de mudanças no quadro legal do sistema multilateral de comércio, que ainda era caracterizado pela plena igualdade de direitos e obrigaçôes, no quadro do Gatt, entre partes contratantes desenvolvidas e em desenvolvimento. O Brasil foi um dos articuladores mais ativos das propostas desenvolvimentistas que resultaram na criação, em março de 1964, da Conferência das Nações Unidas sobre Comércio e Desenvolvimento (Unctad), cujos objetivos eram a revisão completa da arquitetura do sistema multilateral de comércio e a criação de mecanismos — sustentação de produtos de base, sistema geral de preferências comerciais em favor dos exportadores de matérias-primas, não reciprocidade nas relações de comércio - que se acreditava suscetíveis de promover uma inserção mais ativa dos países em desenvolvimento na economia mundial. Um dos resultados do esforço então conduzido foi traduzido na introdução de uma Parte IV - Comércio e Desenvolvimento - no Acordo Geral, relativa à não exigência de reciprocidade estrita, e portanto criando um tratamento diferencial e mais favorável, em favor desses países.

No plano do comércio exterior, a conjuntura é extremamente favorável ao Brasil, mercê das reformas monetárias e cambiais introduzidas nessa mesma fase como a política de mini-desvalorizações cambiais adotada a partir de 1968 -, das políticas setoriais introduzidas numa fase de pouco rigor, no Gatt, com medidas de apoio interno e de subsidiamento explícito da produção e da exportação - como as práticas extensivas de desgravação e estímulos fiscais, de retornos e compensações tributárias -, bem como das facilidades existentes nos planos interno e externo para o financiamento de operaçôes de comércio exterior - com disponibilidade de liquidez, 
a juros baixos, nas duas vertentes -, para não mencionar a grande expansão do comércio internacional nessa fase, com a melhoria significativa dos termos de troca a partir da valorização dos preços das commodities exportadas. A relativa leniência do regime do Gatt em relação aos sistemas nacionais de subvenção às exportações não impediu o surgimento dos primeiros conflitos comerciais bilaterais entre o Brasil e os Estados Unidos, nesta fase ainda limitados às exportaçóes brasileiras de calçados, café solúvel e alguns outros poucos produtos manufaturados, que o governo daquele país acusava serem objeto de dumping.

Graças aos mecanismos de apoio ao comércio exterior criados pelo governo nesse período operou-se não só o aumento do volume transacionado, como também uma diversificação progressiva da pauta e do perfil geográfico das exportações brasileiras. Paralelamente, a conta de serviços e rendas do capital passa a acusar crescentes saldos negativos, como resultado das remessas de juros e lucros, reflexo, por sua vez, da forte captação de recursos externos - empréstimos e investimentos -, ademais dos pagamentos por fretes. $\mathrm{O}$ déficit de transaçóes correntes passa de pouco menos de US\$ 300 milhões em 1967 para mais de US\$ 2 bilhôes em 1973, movimento compensado pelo aumento substancial da dívida externa, que passa de US\$ 3,4 bilhões para US\$ 14,9 bilhões no mesmo período.

As exportações e importações cresceram vigorosamente no período, em especial entre 1968 e 1973, a taxas acumuladas de $275 \%$ e $330 \%$, respectivamente. Do lado das exportaçôes, a expansão foi especialmente vigorosa nos manufaturados, ao passo que as importaçōes refletiram sobretudo a dependência brasileira em combustíveis e bens de capital. A tabela seguinte revela, para esse período, as mudanças incrementais na composição da pauta exportadora do Brasil.

Brasil: exportações de bens, 1964-1974 (US\$ milhões e \% sobre o total)

\begin{tabular}{c|c|c|c|c|c|c}
\hline Anos & Básicos & Semi-Manufat. & Manufaturados & Total & \% Básicos/Total & \% Manuf./Total \\
\hline 1964 & 1.221 & 115 & 90 & 1.430 & 85,4 & 6,2 \\
\hline 1965 & 1.301 & 154 & 130 & 1.595 & 81,5 & 8,1 \\
\hline 1966 & 1.445 & 141 & 152 & 1.741 & 82,9 & 8,7 \\
\hline 1967 & 1.302 & 147 & 192 & 1.654 & 78,7 & 11,6 \\
\hline 1968 & 1.493 & 179 & 199 & 1.881 & 79,3 & 10,5 \\
\hline 1969 & 1.798 & 213 & 279 & 2.311 & 77,8 & 12,0 \\
\hline 1970 & 2.051 & 251 & 410 & 2.739 & 74,8 & 14,9 \\
\hline 1971 & 1.989 & 247 & 573 & 2.904 & 68,5 & 19,7 \\
\hline 1972 & 2.674 & 391 & 881 & 3.991 & 67,0 & 22,0 \\
\hline 1973 & 4.053 & 568 & 1.418 & 6.199 & 65,3 & 22,8 \\
\hline 1974 & 4.576 & 919 & 2.262 & 7.951 & 57,5 & 28,4 \\
\hline
\end{tabular}

Fonte: site do Banco Central; cálculos do autor. 


\section{A desordem monetária internacional e o desequilíbrio financeiro: 1973-1982}

Não obstante os grandes fluxos de IED, predominaram no período os empréstimos em moeda, o que teria efeitos potencialmente perigosos na fase seguinte, sobretudo considerando-se o fato de que, em 1971, chega-se ao final do padrão cambial estável, isto é, de taxas fixas mas ajustáveis, determinado em 1944: a inflação do dólar e o acúmulo de reservas nessa moeda pelos outros países industrializados desmontariam o padrão monetário fixado em Bretton Woods.

Esse sistema entrou em colapso em agosto de 1971, quando, sem prévio aviso, os Estados Unidos declararam não mais honrar o compromisso assumido em 1944 e suspenderam unilateralmente a conversibilidade do dólar em ouro. Esforços tendentes a restaurar o equilíbrio com base em novas paridades fracassaram e, a partir de 1973, com as modificações pertinentes introduzidas no convênio constitutivo do FMI, a economia mundial passou a viver num regime de ausência total de paridades correlacionadas. Embora a maioria dos países tenha passado a adotar um regime baseado na flutuação cambial, vários outros, em especial os países em desenvolvimento, continuaram a vincular suas moedas a algumas divisas fortes.

Nesse mesmo período, os fluxos de IED continuaram importantes, numa fase em que eles já eram cruciais para a manutenção do equilíbrio do balanço de pagamentos, fortemente deficitário em vários anos do período decenal que termina em 1984. Por isso mesmo, a mobilização de recursos externos para compensar as saídas financeiras - amortizações de capitais compensatórios - e os déficits de transaçôes correntes - rendas de IED, juros da dívida e royalties e serviços técnicos, ademais das importações - alcançou patamares que jamais tinham sido vistos na história econômica brasileira e que não mais seriam reproduzidos nas fases subseqüentes. A tabela abaixo dá continuidade aos indicadores selecionados nessas duas rubricas.

Investimento estrangeiro direto e poupança externa, 1974-1984

\begin{tabular}{l|c|c|c|c|c|c|c|c|c|c|c}
\hline & 1974 & 1975 & 1976 & 1977 & 1978 & 1979 & 1980 & 1981 & 1982 & 1983 & 1984 \\
\cline { 2 - 11 } IED (US\$ milhões) & 1154 & 1095 & 1219 & 1685 & 2056 & 2210 & 1544 & 2315 & 2740 & 1138 & 1459 \\
\hline Poupança Ext./PIB & 6,84 & 5,42 & 4,20 & 2,74 & 3,49 & 4,84 & 5,37 & 4,54 & 6,00 & 3,55 & $-0,05$ \\
\hline
\end{tabular}

Fontes: IBGE e Banco Central, in Giambiagi et alii (orgs.), Economia Brasileira Contemporânea.

\section{Crises sucessivas e estrangulamento do crescimento econômico a partir de 1973}

A despeito de essa fase ter sido marcada por choques externos, déficits de transações correntes e acumulação de dívida externa, o período se inicia de 
maneira bastante otimista. Em 1973, a economia mundial crescia a 7\% ao ano e o Brasil teve uma expansão que foi o dobro de sua taxa histórica; a expansão do crédito bancário se dava na esteira das inovaçóes associadas aos mercados de euromoedas; o valor das exportaçôes dos países em desenvolvimento para as economias avançadas vinha crescendo a uma taxa média anual de $18 \%$ desde 1966; a própria inflação era vista com complacência em quase toda parte, já que a variação cambial acrescentava um elemento a mais de gestão macroeconômica ${ }^{18}$. Nesse mesmo ano, o regime de flutuação cambial torna-se a norma no FMI, criando uma série de constrangimentos cujo impacto sobre a economia brasileira se faria sentir em menos de dois anos.

Antes disso, a quadruplicação dos preços do petróleo, no final desse ano, representou a transferência de $2 \%$ da renda mundial em favor dos exportadores dessa commodity estratégica e um severo golpe nas contas externas do Brasil, país dependente do petróleo estrangeiro para quatro quintos de seu consumo total: em função desse aumento, o valor das importações excedeu o das exportações em US \$ 4,7 bilhões em 1974. ${ }^{19}$ Como recordou um dos protagonistas chaves da política econômica nesse período, o ministro do Planejamento Reis Velloso, "a crise do petróleo simplesmente inviabilizou o modelo do período do milagre, que era altamente dependente de importações de petróleo, de produtos intermediários, o que chamávamos de insumos industriais básicos, além, evidentemente, de equipamentos" 20 .

A dívida externa total passa de US\$21.171, em 1975, para US\$43.510, em 1978, e US\$ 49.904, no final de 1979. Tendo dado garantias federais aos contratos de dívida externa, as autoridades econômicas atuavam como se fosse infinitamente elástica a oferta de crédito externo para o país. Depois do período de "hiato de recursos" (1974-76), para financiar os investimentos, passa-se a uma fase puramente financeira da contratação de recursos externos. Com efeito, para contornar o problema da retração progressiva das captaçôes privadas a partir dessa época, é operada um verdadeira "estatização" da dívida externa, envolvendo as já referidas garantias federais e intensa utilização das empresas estatais ${ }^{21}$. Ao mesmo tempo, o governo promove uma política comercial fortemente protecionista: a participação das importações no PIB, que, em 1974, correspondia a 12\% - um recorde histórico, semelhante ao atingido em 1954 -, caiu para apenas 7,25\% em 1978. O esforço de expansão das exportações logrou resultados, uma vez que elas duplicaram entre 1973 e 1978, passando de US \$ 6,2 bilhões para US\$12,7 bilhões.

18 Cf. Dionísio Dias Carneiro, “Crise e Esperança: 1974-1980" in Abreu (org.), A Ordem do Progresso, op. cit., p. 295-322, p. 295.

19 As importações passaram de US\$ 6,2 bilhōes para 12,6 bilhōes, em 1974, sendo que a fatura petrolífera passou de US $\$ 710$ milhões em 1973 para 2,8 bilhōes em 1974, com uma diminuição concomitante das reservas internacionais e um grande aumento na dívida externa.

20 Cf. João Paulo dos Reis Velloso, Tempos Modernos: memórias do desenvolvimento. Rio de Janeiro: Editora FGV, 2004; organização de Maria Celina D’Araujo e Celso Castro, p. 225.

21 Ver, a esse propósito, o estudo de Paulo Davidoff Cruz, Dívida Externa e Politica Econômica: a experiência brasileira nos anos setenta. São Paulo: Brasiliense, 1984. 


\section{A crise da dívida externa em 1982 e a descida para o abismo}

A nova crise do petróleo, em 1979, agravou ainda mais a situação das transaçóes correntes, numa fase em que as taxas de juros passam a ser flutuantes e de fato aumentam extraordinariamente a partir da política do Federal Reserve de atrair capitais para os Estados Unidos. O governo Figueiredo, novamente com Delfim Neto à frente da economia, hesitou entretanto em recorrer ao FMI, na medida em que o apelo teria um enorme custo político. Ele só o fez quando a situação já tinha saído de controle, com escassez de capitais voluntários a partir da guerra das Malvinas (maio de 1982) e sobretudo com o deslanchar da moratória mexicana em agosto desse ano.

Entre o início de 1983 - quando é negociado um acordo dito EFF (extended Fund facility), por um valor de 4,2 bilhões de Direitos Especiais de Saque, sem que esse total fosse efetivamente utilizado - e o final do regime militar, o Brasil beneficiouse de créditos emergenciais do Fundo, mas não conseguiu cumprir a maior parte das exigências e requerimentos formulados pelo staff do órgão e estabelecidos pela diretoria, pois não tinha condições políticas para empreender reformas tendentes a desindexar a economia e a colocar as contas públicas sob controle. $\mathrm{O}$ ministro Delfim Neto negociou e renegociou meia dúzia de cartas de intençôes para sustentar um acordo stand-by que nunca foi implementado em forma integral.

Se já era difícil a situação da dívida externa oficial, que teria de ser negociada no âmbito do Clube de Paris, mais grave era o problema da dívida comercial, para a qual os instrumentos de coordenação ainda eram incipientes e improvisados. A estrutura dos empréstimos consorciados, envolvendo dezenas, senão centenas de bancos - os chamados syndicated loans - era obviamente uma complicação adicional: um comitê assessor dos bancos credores foi rapidamente constituído, mas seu funcionamento deixava bastante a desejar em face das disputas entre os próprios bancos para um tratamento preferencial para os seus créditos.

A inadequação dos mecanismos institucionais para o encaminhamento adequado do problema da dívida externa era patente. Por um lado, os bancos privados tinham sido extremamente irresponsáveis ao conceder empréstimos sobre empréstimos aos governos dos países em desenvolvimento, na suposição absurdamente anti-histórica de que Estados soberanos não vão à bancarrota e não declaram moratória. Eles estavam esperando que o governo dos Estados Unidos e o próprio FMI garantissem pelo menos o pagamento dos juros por parte dos países devedores, algo que esteve sob risco em diversas ocasiōes. Por outro lado, o FMI estava apenas equipado para tratar de desequilíbrios temporários de balanço de pagamentos, não para administrar um processo prolongado de renegociação de dívidas soberanas e comerciais. Uma solução parcial só seria encontrada no final da década, quando se estabelece um esquema de redução do valor de face da dívida, num esquema negociado de troca de títulos velhos por novos títulos garantidos por colaterais concebidos sob a liderança do Tesouro dos EUA (Brady bonds). 
A fase final do regime militar, marcada pela crise da dívida externa, desenvolve-se numa atmosfera de graves turbulências econômicas e políticas, caracterizada, entre outros elementos, pelo movimento em prol de eleições diretas para a presidência da República. Nesse período, era nítido o contraste entre os principais indicadores macroeconômicos (crescimento, taxa de inflação, contas externas) dessa fase com aqueles que tinham caracterizado o período do "milagre econômico", como a tabela abaixo pode demonstrar.

Indicadores econômicos do período militar, 1970-1984

\begin{tabular}{|c|c|c|c|c|c|c|}
\hline \multirow{2}{*}{ Ano } & \multicolumn{2}{|c|}{ Crescimento do PIB (\%) } & \multirow{2}{*}{$\begin{array}{l}\text { * Balanço de } \\
\text { Pagamentos }\end{array}$} & \multirow{2}{*}{$\begin{array}{l}\text { * Dívida } \\
\text { externa }\end{array}$} & \multirow{2}{*}{ Dívida/PIB } & \multirow{2}{*}{$\begin{array}{l}\text { Taxa de } \\
\text { Inflação }\end{array}$} \\
\hline & Total & per capita & & & & \\
\hline 1970 & 10,4 & 7,2 & -562 & 5.295 & 12,5 & 19,5 \\
\hline 1971 & 11,3 & 8,6 & -1.307 & 6.622 & 13,3 & 20,3 \\
\hline 1972 & 12,1 & 9,4 & -1.489 & 9.521 & 16,3 & 17,3 \\
\hline 1973 & 14,0 & 11,3 & -1.688 & 12.572 & 15,9 & 14,9 \\
\hline--- & --- & --- & --- & --- & --- & -- \\
\hline 1981 & $-3,1$ & $-5,3$ & -11.734 & 61.411 & 23,3 & 109,9 \\
\hline 1982 & 1,1 & $-1,2$ & -16.310 & 70.198 & 25,8 & 95,5 \\
\hline 1983 & $-2,8$ & $-5,0$ & -6.837 & 81.319 & 39,4 & 154,5 \\
\hline 1984 & 5,7 & 3,4 & 45 & 91.091 & 43,1 & 220,6 \\
\hline
\end{tabular}

Fonte: IBGE; ${ }^{*}=\mathrm{US} \$$ milhões

Pano rápido:

a cortina não conclusiva da longa fase de lento crescimento

As cifras desalentadoras da última fase do regime militar representariam o início de um longo ciclo descendente da economia brasileira que se prolongaria até o começo do século XXI. O período seguinte, não examinado neste trabalho, coincide com a redemocratização do país, quando se vive a "instabilidade sem desenvolvimento", ou seja, uma forte deterioração da situação econômica, com a aceleração do processo inflacionário, a queda sensível no ritmo de crescimento e tentativas frustradas de estabilização, até se conseguir alcançar um cenário de relativa estabilidade, a partir do Plano Real (1994). Ainda aqui, se vive novo período de crises e de fragilidades no plano externo, na medida em que o país sofre os efeitos da globalização financeira, num momento em que ele teve de apoiar a sua estabilidade em altos juros e câmbio valorizado. No período recente, sobretudo a partir da desvalorização de 1999 e da introdução do regime de metas de inflação - com a adoção paralela da lei de responsabilidade fiscal -, podese sugerir que a economia brasileira, finalmente, parece ter garantido sua tão 
almejada estabilidade, sem que, no entanto, ela tenha conseguido retomar as altas taxas de crescimento econômico observadas na fase anterior às crises do petróleo e da dívida externa.

A aparente superação da vulnerabilidade financeira externa se dá no bojo de uma fase excepcionalmente positiva da economia internacional, com nova valorização cambial e acumulação de reservas internacionais em volumes inéditos na história econômica do país. O governo pretende realizar um projeto de "inserção soberana" na globalização, com o que se chama de retomada do "social-desenvolvimentismo", na verdade impulsionado por uma nova agenda de ativismo estatal.

Caberia verificar, ao fim e ao cabo, quanto se conseguiu em termos de estabilização efetiva e de inserção ativa na economia mundial. Tendo em vista as características singulares de um "projeto nacional informal" das elites, a impressão que se tem é a de que o Brasil realizou uma inserção defensiva na globalização, da qual resulta uma interdependência limitada de seu sistema nacional, com resultados, portanto, mitigados, em termos de modernização econômica e social. Os efeitos transformadores da fase recente não são, contudo, suficientemente explícitos para que se possa concluir que o Brasil adentrou, efetivamente, num ciclo diferente, que seria presumivelmente virtuoso, de seu processo de desenvolvimento econômico, com plena integração aos circuitos mais dinâmicos da economia mundial. A história recente das relações econômicas internacionais do Brasil merece ser escrita talvez com um pouco mais de recuo no tempo.

Recebido em 20 de agosto de 2007 Aprovado em 30 de novembro de 2007

\section{Resumo}

Ensaio histórico sobre as relações econômicas internacionais do Brasil dos anos 1950 aos 80 , evidenciando as mudanças nos principais fluxos comerciais e financeiros, no quadro da economia mundial. O Brasil preserva uma postura defensiva, em função de restrições cambiais e de fragilidades financeiras que são recorrentes nesse período.

\section{Abstract}

Historical essay on international economic relations of Brazil since the 1950s up to the end of military regime, in 1985. Important changes are observed in the main flows in trade and finance, within world economy. Brazil keeps its defensive stance, in order to adjust to serious exchange restrictions and financial fragilities, a recurring trend during that period.

Palavras-chave: Economia brasileira, inserção internacional, comércio, finanças, investimentos. Key-words: Brazilian economy, world integration, trade, financing and direct investiments. 